\title{
Chuí, uma extensão do Oriente Médio na América Latina: A migração Palestina e a contribuição da cultura árabe na Fronteira Meridional do Brasil
}

\author{
Chuí, una extensión del Oriente Medio en Latino América: La migración \\ Palestina e la contribución de la cultura árabe en la frontera sur de Brasil \\ Chuí, an extension of the Middle East in Latin America: Palestinian \\ migration and the contribution of Arab culture in the Brazilian Southern \\ border
}

\author{
Luciano Alexandrino dos Santos Junior ${ }^{1}$ \\ José Carlos da Silva Cardozo ${ }^{2}$
}

\begin{abstract}
Resumo
O estudo analisa o cenário contemporâneo multicultural no extremo sul do Brasil nas cidades gêmeas Chuí-Chuy (Brasil- Uruguay) com ênfase na cultura árabe decorrente dos fluxos migratórios. Visa-se apresentar a relevância da cultura árabe e seus papéis sociais na cooperação local e formação de políticas de aperfeiçoamento dos serviços básicos da população. O trabalho parte do ápice dos conflitos étnicos, religiosos e territoriais entre os países do Oriente Próximo, na década de 1970, enfocando os palestinos, em disputas territoriais com o estado de Israel. Tal como elucida um provérbio árabe de que o exílio com riqueza é uma pátria e uma pátria com pobreza é um exílio, muitos indivíduos e famílias fugiram dos conflitos e buscaram construir uma nova vida na América Latina e encontraram nas regiões de fronteira o ambiente para trabalharem e manifestarem sua cultura e religião de maneira prospera. Conclui-se que a cultura árabe na região estudada se tornou uma importante ferramenta de desenvolvimento social, bem como estimula a ação coordenada entre comerciantes, cidadãos e grupos da sociedade civil, modificando a ideia de fronteira como fator de separação para a de um ambiente de integração.
\end{abstract}

Palavras-Chave: Chuí; Cultura árabe; Cooperação; Imigração Palestina.

\section{Resumen}

El estudio analiza el entorno contemporáneo multicultural en el extremo sur de Brasil en el las ciudades gemelas Chui-Chuy (Brasil-Uruguay), con énfasis en la cultura árabe como resultado de los flujos migratorios. Se trata de presentar la importancia de la cultura árabe y sus roles sociales en la cooperación local y la mejora de la formación política de los servicios básicos de la población. El trabajo empieza del la vértice de los conflictos étnicos, religiosos y territoriales entre los países del Cercano Oriente, en la década de 1970,

\footnotetext{
${ }^{1}$ Graduando do curso de Relações Internacionais, terceiro semestre; Universidade Federal do Rio Grande FURG; Santa Vitória do Palmar, Rio Grande do Sul, Brasil; luciano.alexandrinojr@gmail.com. Trabalho apresentado no I Seminário Latino-Americano de Estudos em Cultura - SEMLACult, Foz do Iguaçu/PR, Brasil, 2017.

2 Pós-Doutor em História Latino-Americana pela UNISINOS; professor substituto do curso de Relações Internacionais da Universidade Federal do Rio Grande - FURG; Santa Vitória do Palmar; Rio Grande do Sul; Brasil; jcs.cardozo@gmail.com. Trabalho apresentado no I Seminário Latino-Americano de Estudos em Cultura - SEMLACult, Foz do Iguaçu/PR, Brasil, 2017.
} 
centrándose en los palestinos en disputas territoriales con el estado de Israel. Como aclara un proverbio árabe que el exilio con la riqueza es un país y un país con la pobreza es un exilio, muchos individuos y familias huyeron del conflicto y trataron de construir una nueva vida en América Latina y se encuentran en las zonas fronterizas un lugar para trabajar y expresar su cultura y religión de manera prospera. Se llega a la conclusión de que la cultura árabe en la región estudiada se ha convertido en una herramienta importante para el desarrollo social, y también anima a la acción coordinada entre los comerciantes, ciudadanos y grupos de la sociedad civil mediante la modificación de la idea de frontera como factor de separación para un lugar de integración.

Palabras claves: Chuí; Cultura árabe; Cooperación; Inmigración Palestina.

\begin{abstract}
The study analyzes the contemporary multicultural scenario in the extreme south of Brazil in the Chuí-Chuy twin cities (Brazil-Uruguay) with emphasis on the Arab culture due to migratory flows. It is intended to present the relevance of Arab culture and its social roles in local cooperation and the formation of policies to improve the basic services of the population. The work starts from the height of ethnic, religious and territorial conflicts between the countries of the Middle East in the 1970s, focusing on Palestinians in territorial disputes with the state of Israel. As an Arab proverb says that exile with wealth is a homeland and a homeland with poverty is an exile, many individuals and families fled the conflicts and sought to build a new life in Latin America and found in the border regions the environment to work and to manifest their culture and religion in a prosperous way. It is concluded that the Arab culture in the region studied has become an important tool for social development, as well as stimulates the coordinated action among traders, citizens and civil society groups, modifying the idea of border as separation factor to one of integration.
\end{abstract}

Keywords: Arab Culture; Chuí; Cooperation; Palestinian Immigration

\title{
1. Introdução
}

A imigração palestina iniciou-se em meados do fim da segunda guerra mundial, com a criação do Estado de Israel em 1948 que culminou em um interminável conflito na região, muitos Estados árabes vizinhos não reconhecem a legitimidade do Estado da Palestina, seus cidadãos tem dificuldade para retirar simples documentos, adquirir vistos, identidades e direitos fundamentais, uma condição mínima de vida que qualquer cidadão poderia obter ao viver em um Estado. Desde então os palestinos são um terço da população refugiada em todo o mundo (Nabulsi, 2003, p.49-54), os palestinos além de possuírem suas próprias demandas como o reconhecimento de suas terras históricas e religiosas, de viajar e se instalar em qualquer região do Oriente Médio, tal povo deseja acima de tudo um ambiente sem guerras armadas, que consigam se desenvolver e manifestar sua cultura. Ademais, os fluxos migratórios em altos índices advindos do Oriente Médio não se restringem somente aos palestinos, mas também de outros povos árabes oriundos da Jordânia, Turquia e Síria. Tais 
fluxos migratórios se devem pelas condições econômicas e sociais precárias e ausência de condições fundamentais para a vida e desenvolvimento humano.

Diante do cenário atual de integração conferido pela globalização mais do que nunca a questão das fronteiras entram em destaque. Nesse aspecto, o presente trabalho discorre sobre o tema de estudo da cultura estrangeira árabe e imigração palestina que tem mudado o sentido e a função da fronteira no extremo sul brasileiro diante da atual conjuntura que se apresenta em novos usos do território.

O intenso comércio é considerado um dos atores de integração das regiões fronteiriças. É importante destacar que o comércio internacional é sempre visto como um caminho para a expansão do mercado e para um maior crescimento do setor moderno, conforme estudos de Jackson e Sorensen (2003, p.279). Por possuir uma configuração espacial peculiar, as fronteiras secas com conturbações urbanas, as chamadas cidades-gêmeas são as maiores responsáveis pelas trocas comerciais e pelo fluxo intenso de pessoas entre os países.

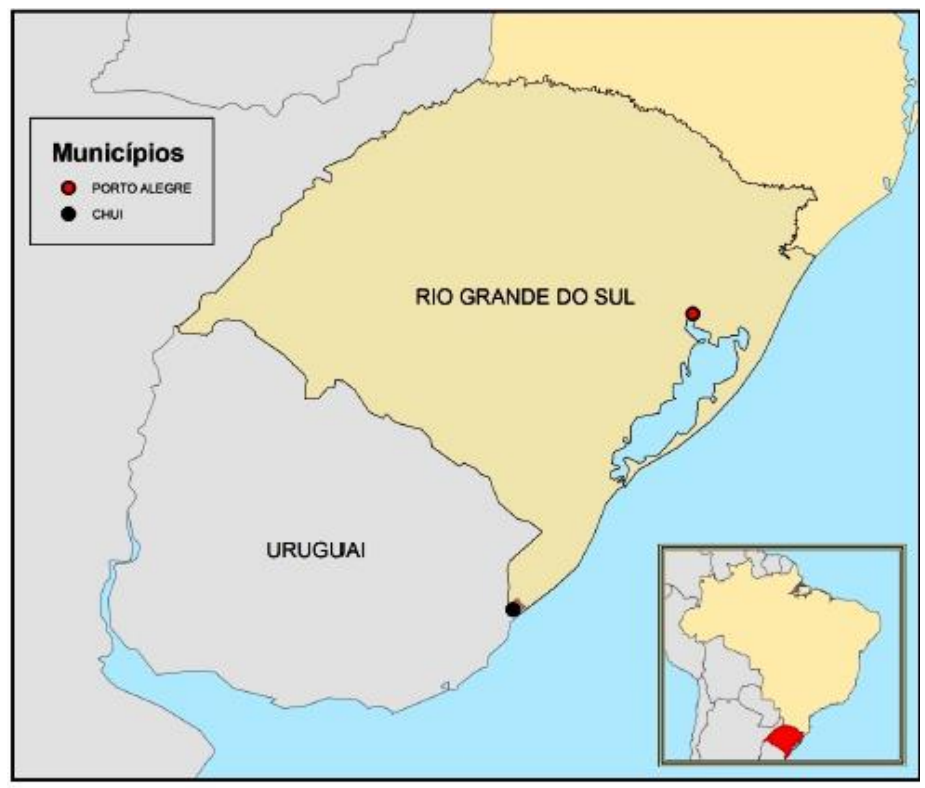

FIGURA 1- Mapa de localização do Chuí. Base cartográfica: http://www.diva-gis.org/gdata

É preciso pensar na importância da miscigenação cultural nessas cidades como elo entre os cidadãos que buscam os mesmos benefícios sociais. As associações religiosas, organizações não governamentais (ONGs) e organizações da sociedade civil personificam a cultura dos povos que ali vivem, como por exemplo, o clube árabe no Chuí, que contribui grandemente para a promoção e manutenção da cultura árabe, do idioma árabe, de eventos culturais, religiosos, casamentos, encontros árabes e da gastronomia árabe, mesmo estando a milhares de milhas do Oriente. O presente estudo disserta sobre a importância e contribuição 
da cultura árabe decorrente da imigração palestina na região e sua capacidade de transformar a concepção de fronteiras de uma região conflituosa e insegura para um local de cooperação e coexistência cultural.

\section{A diáspora Árabe e a imigração Palestina}

Para entender a diáspora árabe com ênfase na imigração Palestina sobre a América Latina e como se tornaram um dos povos mais deslocados e refugiados do fim do século $\mathrm{XX}$ temos que olhar para a história, a partir da formação do território Palestino no oriente médio em uma das regiões mais estratégicas de locomoção da região e a fundação do Estado de Israel. O território que hoje corresponde à Palestina e Israel foi palco de grandes conflitos por ser uma região estratégica entre o norte do continente Africano e o sudoeste Asiático formando um corredor natural onde passavam diversos exércitos das civilizações antigas. Nesse sentido, o auge da diáspora palestina e árabe se deu por meio da criação do Estado de Israel que visava por fim aos conflitos étnicos e religiosos. Entretanto, tal ação acirrou ainda mais os conflitos entre eles, ocasionando em milhares de mortes, deslocados e conflitos armados entre as potências árabes e até com a intervenção de grandes países ocidentais como os Estados Unidos da América e a União das Repúblicas Socialistas Soviéticas no período da Guerra-Fria.

Em 1948 a Organização das Nações Unidas (ONU) através da Assembleia Geral determinou a divisão da parte ocidental da Palestina entre um Estado Judeu e outro um Estado Árabe baseado na identidade étnica e religiosa da população. No mesmo ano o Estado de Israel declararam sua constituição, já os árabes que haviam formado $15 \%$ de tal território recusaram a partilha.

Com isso, alguns países árabes como a Jordânia, Síria, Líbano, Arábia Saudita, Iraque e Iémen além do Egito declararam Guerra ao recém-formado Estado judeu. Nos meses seguintes, na chamada Guerra da Independência, Israel perde cerca de 1\% da sua população, mas sairia vencedora, formando um país maior que o inicialmente proposto pelas Nações Unidas dois anos antes. Egito e Jordânia ocupam o território restante, Gaza, Judeia e Samaria.

Em 1967 acontece a Guerra dos seis dias, em que novamente Egito, Jordânia e Síria juntamente com Líbano, Arábia Saudita e Iraque planejaram uma nova ofensiva e mobilizam os seus exércitos com o objetivo de destruir o Estado de Israel. Todavia, Israel derrotou os seis exércitos em várias ocasiões ao longo desses anos, ocupando a península 
do $\underline{\text { Sinai }}$ (Egito), Colinas de Golã (Síria) e Cisjordânia (Jordânia). Além disso, conquistaram o total controle sobre a cidade de Jerusalém. Desde então Israel adotou uma política externa voltada a instalações de bases militares e pequenos povoados civis para assegurar suas fronteiras e expandir sua influência como um Estado soberano. Com isso, os povos da fronteira oeste de Israel de maioria muçulmana, denominados Palestinos lutam pelo reconhecimento de um Estado soberano e pela reconquista de territórios históricos incorporados à Israel.

A ONU concedeu o título de membro observador e sua independência foi declarada em 15 de novembro de 1988 pela Organização para a Libertação da Palestina (OLP) que reivindica a soberania sobre os territórios palestinos e designa a cidade de Jerusalém como sua capital, bem como outros territórios ocupados por Israel desde a Guerra dos Seis Dias. Atualmente, o governo do país em questão é a denominada Autoridade Nacional Palestina que realiza apenas a administração sócio-política em áreas delimitadas dos territórios desde os Acordos de Oslo em 1993.

Nesse aspecto, os cidadãos que se autodenominavam Palestinos residentes nos territórios ocupados por Israel ou até afetados pelos sangrentos conflitos armados na região foram forçados a buscar auxilio em outras nações ao redor do mundo. Porém, tal refúgio não fora encontrado nem mesmo em alguns países árabes que não reconhecem o movimento emancipatório palestino e nem em países Europeus que possuem políticas migratórias extremamente rígidas. Com isso, a América Latina tornou-se uma oportunidade de destino não só para os Palestinos, mas também para diversos povos árabes por proporcionar liberdade cultural e religiosa, além de oportunidades empregatícias.

Atualmente, as fronteiras internacionais na América Latina configuram uma nova noção de controle estatal e com um intenso fluxo de pessoas e bens. Assim como afirma JARDIM (2000, p.72) os imigrantes árabes possuem um forte apreço pelas regiões de fronteira por estas proporcionarem grandes oportunidades comerciais e certa distância das rotinas estatais de fiscalização. Portanto, a presença dos palestinos e demais imigrantes orientais possuem uma enorme relevância no comércio e desenvolvimento local caracterizando-as como fronteiras em expansão e com múltiplas identidades étnicas.

\subsection{A cultura árabe e a construção de uma fronteira multicultural}


A cultura árabe engloba tradições e costumes que possuem uma história comum em territórios do Oriente Médio, África Setentrional e Ásia Ocidental, envolvendo povos muçulmanos, judeus e cristãos e manifesta-se através da literatura, música, gastronomia, arte, arquitetura, espiritualidade, filosofia e principalmente o idioma árabe.

De uma forma geral a cultura árabe possui valores em comum como a lealdade, tradicionalismo, conservadorismo e a privacidade. A família é patriarcal onde a mãe é responsável pelos afazeres domésticos e cuidados de casa, enquanto o homem, pai, é o tomador das decisões da casa e da vida familiar. Ademais, as mulheres árabes dificilmente são encontradas com os cabelos descobertos e em alguns lugares são até proibidas de dirigir automóveis ou recitar o Corão; ademais, apesar de não serem proibidas de estudar na maioria das nações arábicas, normalmente elas ficam restritas a escolas femininas. Costumam vestirem-se em comum decoro, utilizando um hijab (tecido que cobre a cabeça sem esconder o rosto) ou outros tecidos e modelos que cobram o corpo todo. Os homens podem ser facilmente encontrados vestidos à moda ocidental com calça jeans e camisa, ou então usando uma mistura de roupas ocidentais e tradicionais como togas e turbantes.

Outro aspecto que evidencia a cultura árabe é a forte influência religiosa e o idioma Árabe. A religião mais comum no universo árabe é o Islamismo. Entretanto, não se deve confundir árabe com muçulmano, pois existe tanto cidadãos como Estados Árabes com fortes índices de adeptos cristãos e judeus.

A língua árabe é um elo entre as diferentes nações do Oriente Médio e através dos imigrantes ao redor do mundo vem tomando novas proporções no cenário internacional. Os árabes estão espalhados por toda a península arábica que é o norte da África, o Líbano, Iraque e a Jordânia. Eles convivem com outros povos e a língua árabe tem algumas diferenças dependendo do local onde está sendo utilizada. O idioma possui três vogais e vinte consoantes, a escrita é feita da direita para a esquerda. Tal sistema é chamado de abjad. A escrita é feita apenas com consoantes, deixando para o leitor a tarefa de complementar com a vogal correta.

Nota-se que mesmo estando à milhas de distâncias da Palestina ou do Oriente Médio os imigrantes Palestinos encontram na América Latina, especificamente, na região fronteiriça das cidades gêmeas Chuí-Chuy uma oportunidade de manifestar sua cultura, costumes e idioma, mesmo fora de sua terra natal. Em tal região é extremamente comum o idioma árabe ser falado no dia-a-dia, principalmente no comércio. Os palestinos fazem do novo território 
onde se inseriram a terra propicia que sempre desejaram ter no Oriente Médio, mas por conta das guerras e conflitos armados eram impedidos de fazê-lo. Nesse sentido, o Clube Árabe no Chuí, local onde se encontram regularmente para expressar suas crenças religiosas, casamentos árabes, festivais e comemorações se tornou um agente propulsor da expansão cultural árabe na região e em muitos momentos a integração entre brasileiros, uruguaios e árabes.

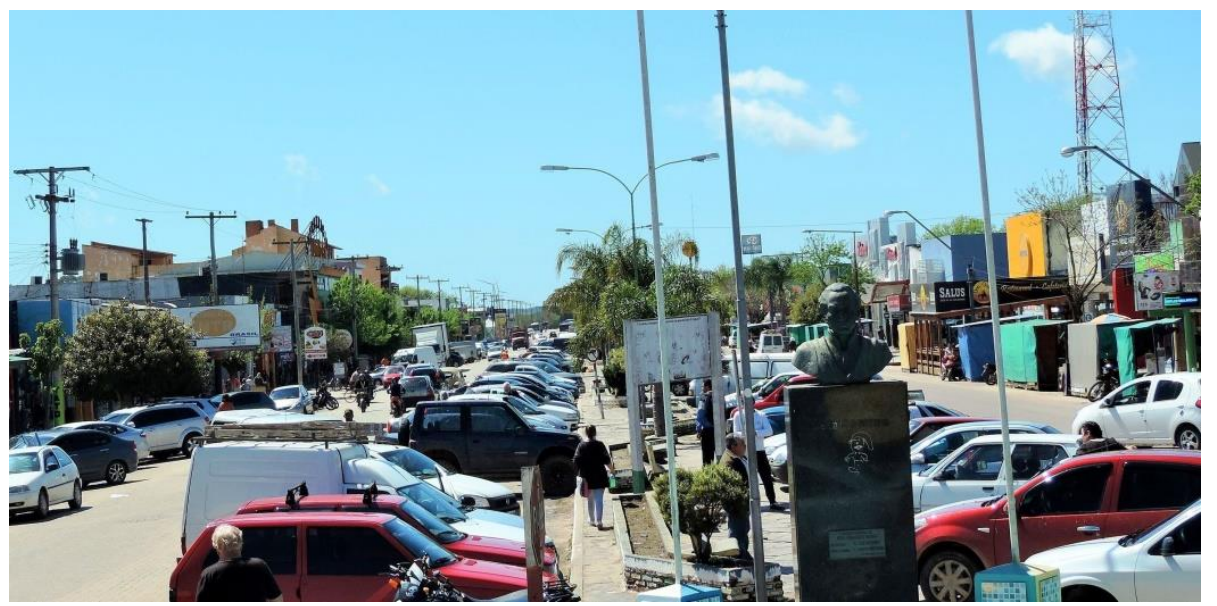

FIGURA 02- Avenida Internacional que separa o Chuí brasileiro na posição esquerda da imagem e o Chuy uruguaio na posição oposta. Fonte: Acervo pessoal do autor/ Pesquisa de campo 2017.

Cabe aqui ressaltar também a influência da riqueza cultural árabe no principal fator de desenvolvimento regional: o comércio. Muitas famílias árabes advindas do Oriente Médio escolhem as cidades de fronteira por terem mais liberdade fiscal para ministrarem seus negócios como lojas de roupas, utensílios domésticos, quinquilharias entre outros. A essência do espirito empreendedor identificado nas famílias árabes esta pautado por princípios culturais da prosperidade individual e familiar.

\section{Conclusões}

As cidades gêmeas Chuí-Chuy localizadas no extremo sul do Brasil na fronteira com o Uruguai destacam-se por um forte índice de migração de povos árabes, com maior índice de imigrantes palestinos que trazem não só experiências, mas também uma rica bagagem cultural, evidenciando culinária, eventos culturais e religiosos como casamentos e assembleias, que ao entrar uma fusão com costumes e tradições uruguaias e brasileiras formam um ambiente multicultural promovendo o desenvolvimento social e cultural através da integração e cooperação. 
A imigração Palestina na América Latina se deu ao longo das décadas por fluxos de diferentes países do Oriente Médio, decorrentes de precárias condições econômicas, sociais e até culturais, onde os indivíduos tinham seus direitos fundamentais violados ora pelo Estado, ora por grupos terroristas, guerras e conflitos armados. O cenário se agravou com a criação do Estado de Israel em 1948 por uma determinação da Assembleia Geral da Organização das Nações Unidas, com isso, diversas disputas territoriais, religiosas e étnicas ganham proporções alarmantes afetando principalmente a sociedade civil, impedindo-os de manifestarem seus diversos aspectos culturais. Milhares de pessoas buscaram construir uma nova vida para seus familiares em terras sul americanas e encontram nas regiões fronteiriças a oportunidade de criar uma extensão do Oriente Médio no outro lado do oceano, manifestando sua cultura, religião e idioma no dia-a-dia e sendo acolhidos pelos habitantes locais, formando um ambiente ímpar de coexistência cultural, respeito e dignidade humana.

Portanto, o presente trabalho buscou compreender a riqueza e herança cultural árabe presentes na fronteira do Chuí decorrentes da imigração palestina e como esta contribui efetivamente para o desenvolvimento local através do intenso comércio praticado pelas famílias árabes. Partindo da integração cultural exposta neste trabalho podem-se compreender outros fenômenos sociais como a identidade cultural e étnica de cidadãos fronteiriços e como estes defrontam com problemas sociais decorridos da ausência fiscal estatal e do contrabando na fronteira.

\section{Referências}

AMARAL, A. F. Os Campos Neutrais. Porto Alegre: Planus Artes Gráficas, 1972. (Obra completa)

AVEIRO, Thaís Mere Marques. Relações Brasil-Uruguai: A Nova Agenda para a Cooperação e o Desenvolvimento Fronteiriço. Brasilia: UNB, 2006. (Dissertação ou Tese)

JACKSON, Robert. Introdução às Relações Internacionais: Teorias e Abordagens. Rio de Janeiro: Zahar, 2003.

JARDIM, D. F. Diásporas, viagens e alteridades: as experiências familiares dos palestinos no extremo sul do Brasil. Horizontes Antropológicos, Porto Alegre, ano6, n.14, 2000.

JARDIM, D. F. Palestinos no extremo Sul do Brasil: Identidade étnica e os mecanismos sócias de produção de etnicidade. Chuí/ RS, 2001. Tese (Doutorado) -PPGAS, Universidade Federal do Rio Grande do Sul/ MN (Impresso \& Cd-Rom) (2000). 
JARDIM, D. F. Palestinos no Sul do Brasil: identidade étnica e cidadania. Projeto (Pesquisa)- PROPESQ/ UFRGS, 2002.

MARTIN, A. R. Fronteiras e Nações. São Paulo: Contexto, 1992. (Obra completa)

NABULSI, K. Los refugiados. In: La Vanguardia. Dossiê. Los Palestinos, n.8, p.49-54, octubre/ diciembre, 2003.

WILlINER, A. At al. Pactos Territoriales en la Construción de Regiones Transfronteirizas: Por uma Mayor Integración a Multiplos Niveles. Santiago: Naciones Unidas, 2016. (Obra completa) 